\title{
Probabilistic Estimation of Corrosion Propagation Period for Prestressed Concrete Structures Exposed to Chlorides
}

\author{
Jayachandran Karuppanasamy and Radhakrishna G. Pillai \\ Department of Civil Engineering, Indian Institute of Technology Madras
}

\section{ABSTRACT}

The overall service life of concrete structures can be divided into corrosion initiation and corrosion propagation phases. The durations of these two phases depend on the chloride threshold $\left(\mathrm{Cl}_{\mathrm{th}}\right)$ and corrosion rate $\left(\mathrm{i}_{\text {corr }}\right)$, respectively, of the embedded steel reinforcement. Quantitative information on $\mathrm{Cl}_{\text {th }}$ and $\mathrm{i}_{\text {corr }}$ of conventional steel reinforcement are available in literature. Now-a-days, the use of prestressed concrete elements are rapidly increasing and there is a dire need for estimating their service life. Quantitative information on the $\mathrm{Cl}_{\text {th }}$ and $\mathrm{i}_{\text {corr }}$ of prestressing steel are required for this estimation. However, very limited quantitative information is available on these parameters. As such, the current practice is to assume that both conventional and prestressing steels have similar $\mathrm{Cl}_{\text {th }}$ and $\mathrm{i}_{\text {corr }}$-which might result in unrealistic estimations.

This paper provides data on $\mathrm{i}_{\text {corr }}$ obtained from a 9-month long experimental program. The $\mathrm{i}_{\text {corr }}$ data was obtained using linear polarization resistance (LPR) tests on prestressing wire embedded in mortar. 10 specimens (made using the center king-wires obtained from 7-wire strands) were cast, cured, and subjected to a cyclic wet-dry exposure using 3.5\% sodium chloride solution. It is observed that the average value of $\mathrm{i}_{\text {corr }}$ of prestressing steel exposed to chloride-contaminated mortar is around $5.8 \mu \mathrm{A} / \mathrm{cm}^{2}$. The paper also provides the probabilistic estimations on corrosion propagation period, $t_{p}$ (defined as the time to crack after corrosion initiation) by substituting the measured $i_{\text {corr }}$ data into two models from literature [i.e., Morinaga (1990) and Wang and Zhao (1993)]. It is found that the estimated average $t_{p}$ for prestressed concrete systems are 5.4 and 9.7 years with large scatter. This paper also provides probabilistic estimations on $t_{p}$ for the prestressed concrete systems with 50,65 , and $80 \mathrm{~mm}$ cover depths.

Keywords: probabilistic, corrosion rate, prestressing steel, service life, corrosion propagation period, time to cracking, prestressed concrete.

\section{INTRODUCTION}

Service life of structures can be defined as the duration for which the structure is able to meet the desired performance with sufficient safety. Many structures are designed and constructed keeping this in mind. However, many of the prestressed concrete structures worldwide, constructed in the last 50 years, have started showing the signs of distress. The major reasons for this distress are overloading, aging of materials, aggressive environmental conditions, corrosion, inadequate maintenance, etc. The presence of oxygen, moisture, and chlorides can lead to the initiation of corrosion of prestressing strands. Once initiated, it is almost impossible to stop corrosion. Due to prolonged corrosion activity, cracking and spalling of the cover concrete surrounding the corroded bars will occur. This can further accelerate the corrosion process, which leads to a reduction in the structural capacity. In order to avoid unexpected/sudden failure and facilitate precautionary measures, the service-life estimation, frequent performance monitoring and maintenance of these structures are essential.

The deterioration process depends on many factors like the quality of concrete, cover depth, the concentration of chloride ions in the ambient environment, temperature and humidity conditions, diffusion coefficient of the concrete and the corrosion rate, $\mathrm{i}_{\text {corr }}$, of the rebars. Among these, the $\mathrm{i}_{\text {corr }}$ is an important parameter required to estimate the corrosion propagation period, $t_{p}$ (defined as time to cracking after the corrosion initiation time, $\mathrm{t}_{\mathrm{i}}$ ). The estimation of $t_{p}$ is necessary for estimating the residual service-life of a structure and determining a 
suitable frequency for monitoring and maintenance activities.

Next section provides the significance of this research. Then, a quick review on the approach for service life estimation (especially, $t_{p}$ ) and Life- $365^{\mathrm{TM}}$ software program is provided. Then, a review of two existing models used to estimate $t_{p}$ is provided. Following this, the details on the experimental program on corrosion rate, $i_{\text {corr }}$, of prestressing steel embedded in cement mortar is provided. Then, the experimental results and probabilistic estimations of $t_{p}$ for systems with 50,65 , and $80 \mathrm{~mm}$ cover depth, $\mathrm{C}_{\mathrm{v}}$, are provided.

\section{RESEARCH SIGNIFICANCE}

Now-a-days, prestressed concrete elements are used in many infrastructure systems. Owners and engineers are often faced with the challenge of estimating the propagation period $\left(\mathrm{t}_{\mathrm{p}}\right)$ of concrete infrastructure systems. The corrosion rate ( $\left.\mathrm{i}_{\text {corr }}\right)$ of the embedded prestressing steel strand is a key parameter required to estimate the $t_{p}$. However, very limited quantitative information is available on the $\mathrm{i}_{\text {corr }}$ of prestressing strands. In fact, the widely used Life- $365^{\mathrm{TM}}$ software program assumes a deterministic value of 6 years as $t_{p}$ for conventional steel reinforcement. Some engineers are using this number for prestressing steel also, which can lead to unrealistic estimations of $t_{p}$. This paper provides experimental data on $\mathrm{i}_{\text {corr }}$ of prestressing steel wires. It also provides a comparative study on $t_{p}$ values estimated by substitution of this data in two models available in the literature. These estimations and the scatter indicate that the deterministic assumption of $t_{p}=6$ years as suggested by Life- $365^{T M}$ may not be suitable and the $t_{p}$ in prestressed concrete structures exhibit large scatter and can be less than that in conventionally reinforced concrete structures. This finding is very valuable and seeks the attention of owners, engineers, and inspectors in ensuring adequate cover depth and quality cover concrete such that both $t_{i}$ and $t_{p}$ is extended as much as possible.

\section{CORROSION PROPAGATION MODELS}

Figure 1 shows the various phases of service life of a structure (Tutti, 1982). When exposed to chloride environment, the chlorides ingress through the cover concrete towards the embedded steel reinforcement.
Corrosion is initiated when the amount chlorides deposited at the steel surface is more than the chloride threshold. This instance is denoted as 'corrosion initiation point' in Figure 1.

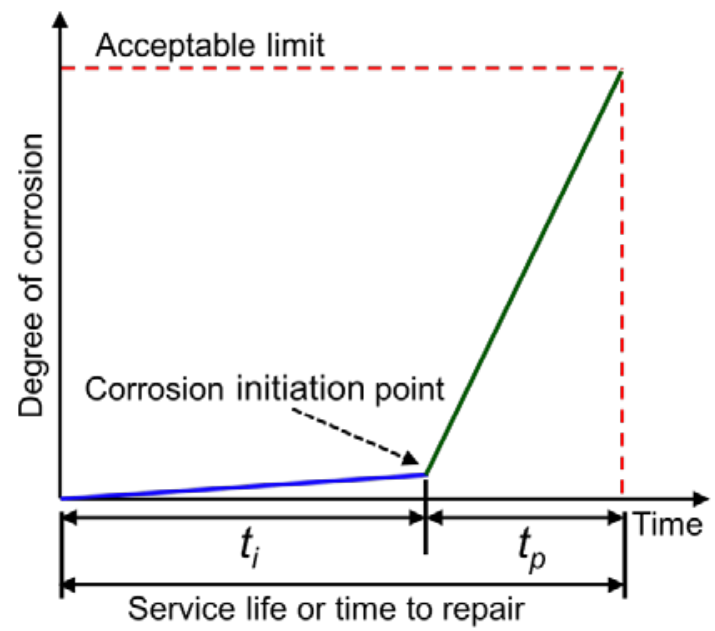

Figure 1. Service life of a reinforced concrete structure exposed to chlorides (Tutti, 1982).

Once corrosion is initiated, the rate of deterioration can be high due to the propagation of corrosion, as indicated by the increase in the slope of the line in Figure 1.

To estimate the overall service life (i.e., $t_{i}+t_{p}$ ) of a structure, the data on (i) surface chloride content $\left(C_{s}\right)$, (ii) chloride diffusion coefficient $\left(D_{c l}\right)$, (iii) critical chloride threshold $\left(\mathrm{Cl}_{t h}\right)$, (iv) corrosion rate $\left(i_{\text {corr }}\right)$, etc. are required. Because of multiple influential factors, the service life model should ideally be non-linear in nature. Therefore, the bilinear assumption in Figure 1 may not lead to an exact estimation for the case in real structures. However, this is a reasonable assumption, especially for estimating $t_{p}$, and has been used by many researchers in the past. Morinaga (1990) and Wang and Zhao (1993) have developed corrosion propagation models with linear assumption on corrosion rate. These models assume $t_{p}$ as the time to cracking after corrosion initiation. Further details on these models are provided in Table 1.

Life- $365^{\mathrm{TM}}$ is a software program used to predict service life and estimate the life-cycle cost of concrete structures exposed to chloride environments. Typical analysis using Life- $365^{\mathrm{TM}}$ model involves the prediction of $t_{i}$ and $t_{p}$. The $t_{i}$ is predicted using finite difference approach using Fick's second law of diffusion and uses a 
probabilistic approach in predicting $\mathrm{t}_{\mathrm{i}}$. However, this program assumes that $t_{p}$ is deterministic and equal to 6 years. Thus, total time to repair $\left(t_{r}\right)$ is equal to $t_{i}+6$ years. This deterministic approach for $t_{p}$ may lead erroneous estimations. A probabilistic approach for estimating $t_{p}$ is required. For this, quantitative experimental data on $\mathrm{i}_{\text {corr }}$ of prestressing steel is required.

Table 1. Two existing models to estimate the corrosion propagation period, $t_{p}$.

\begin{tabular}{|l|l|}
\hline Models to estimate $\mathbf{t}_{\mathbf{p}}$ & Nomenclature \\
\hline Morinaga (1990) & $\Delta$ is the thickness of corrosion product $(\mathrm{mm})$ \\
$t_{c o r}=\frac{Q_{c r}}{J_{r}}$ & $\gamma$ is the crack expansion coefficient of concrete \\
$Q_{c r}=0.602 \times D\left(1+\frac{2 C_{v}}{D}\right)^{0.85}$ & $\rho_{s t}$ is the density of steel $\left(\mathrm{gm} / \mathrm{cm}^{3}\right)$ \\
$J_{r}$ is the thickness of concrete cover $(\mathrm{mm})$ \\
\hline Wang and Zhao (1993) & $D$ is initial diameter of the wire $(5.2 \mathrm{~mm})$ \\
$t_{c o r}=\frac{H}{P_{r}}$ & $F$ is the Faraday's constant $(96500$ Coulombs) \\
$\frac{\Delta}{H}=\gamma=0.33\left(\frac{D}{C_{v}}\right)^{0.565} f_{c u}^{1.436}$ & $f_{c u}$ is the cube strength of concrete $(\mathrm{MPa})$ \\
$P_{r}=\left(\frac{W}{F \rho_{s t}}\right) i_{c o r r}$ & $i_{c o r r}$ is the corrosion rate $\left(\mu \mathrm{A} / \mathrm{cm}{ }^{2}\right)$ \\
\hline
\end{tabular}

\section{EXPERIMENTAL PROGRAM}

\subsection{Specimen design and preparation}

A comprehensive experimental program was conducted to obtain the $\mathrm{i}_{\text {corr }}$ data for prestressing steel. Figure 2 shows a schematic diagram of the corrosion test specimen used in this study.

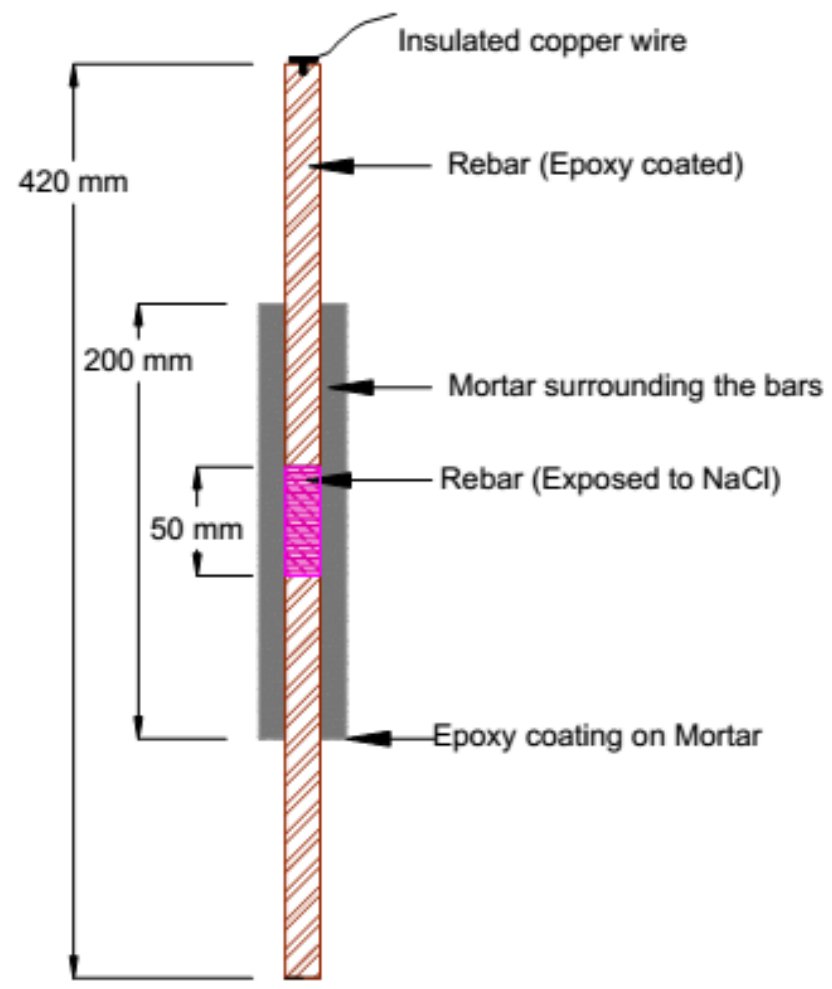

Figure 2. Test specimen with prestressing steel wire embedded in mortar.
Each specimen is prepared using a center king-wire (5.2 $\mathrm{mm}$ diameter; $420 \mathrm{~mm}$ long) extracted from $15.2 \mathrm{~mm}$ diameter 7-wire prestressing strand. Ten such pieces were prepared and cleaned using the ASTM G1 (2011) procedure. To facilitate corrosion measurements, an insulated copper wire (300 mm long) was fastened to one end of the king-wire piece using a screw-thread system. Then, the wire pieces (except the $50 \mathrm{~mm}$ length at the center) and the screw were coated with two thin layers of low viscosity epoxy (Sikadur-52 UF). As shown in Figure 2, the prepared steel pieces were embedded in mortar (with a water:cement:sand ratio of $0.55: 1: 2.75)$. The mortar was prepared using Ordinary Portland Cement (IS: 12269-1987) and silica sand of Grades I, II and III (IS:383-1970).

\subsection{Curing and exposure conditions}

The test specimens were cured in laboratory environment $\left(25^{\circ} \mathrm{C}\right.$ and $65 \% \mathrm{RH}$ approximately) for $24 \pm 1$ hours. After this, the specimens were immersed/cured in saturated limewater for additional 27 days. The cured specimens were subjected to alternate wetting and drying (i.e., 7 days wetting followed by 7 days drying) to accelerate the ingress of chlorides towards the embedded steel piecethereby accelerating the corrosion process. 3.5\% sodium chloride $(\mathrm{NaCl})$ solution was used for the 
wet-dry exposure, which was continued for a period of 10 months under laboratory environment $\left(25^{\circ} \mathrm{C}\right.$ and $65 \% \mathrm{RH}$ ).

\subsection{Corrosion test setup}

At the end of every alternate wetting period, the $i_{\text {corr }}$ of the test specimens were measured using the Linear Polarization Resistance (LPR) technique (Tait, 1994). The Solartron 1287 potentiostat, a 3electrode corrosion cell setup (see Figure 3 ) with a working electrode (WE), a counter electrode (CE), and a reference electrode (RE) were used to conduct the LPR test. The central $50 \mathrm{~mm}$ uncoated region of the steel piece was considered as the WE. A $90 \mathrm{~mm}$ diameter pipe made of Nichrome wire mesh was used as the CE. The test specimen was placed inside this CE. The saturated calomel electrode was used as the RE and was placed close to the surface of mortar. All the electrodes were placed in a glass beaker with $3.5 \% \mathrm{NaCl}$ solution. This formed the corrosion cell as shown in Figure 3. This corrosion cell setup was then connected to a potentiostat and computer for recording the readings, as shown in Figure 4.

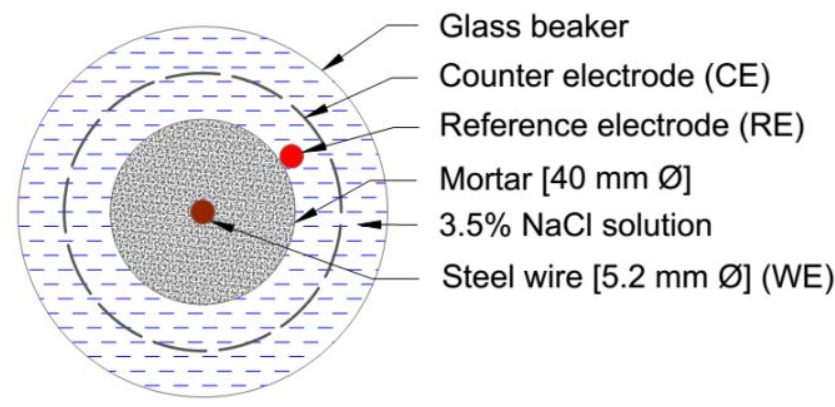

Figure 3. Schematic diagram of the 3 electrode corrosion cell setup (top view).

\subsection{Corrosion measurement method}

Corrosion measurements were made at the end of alternate wetting period (say, once in a month). At first, the Open Circuit Potential (OCP) of the steel specimen was measured. Immediately after measuring the OCP, the LPR test was conducted using a scan range of $\pm 15 \mathrm{mV}$ with respect to the measured OCP of each specimen. A scan rate of $0.1667 \mathrm{mV} / \mathrm{s}$ was used. The measured current (I) was plotted with respect to the applied potential $(E)$ to generate the LPR curve (see Figure 5). The $\mathrm{i}_{\text {corr }}$ is calculated as given in Eq. 1.

$$
i_{\text {corr }}=\frac{B}{R_{p}}=\frac{B}{(\Delta E / \Delta I)}
$$

where, $B$ is the Stern-Geary coefficient, $R_{p}$ is the polarization resistance, $\Delta E$ is the applied potential, $\Delta I$ is the measured current.

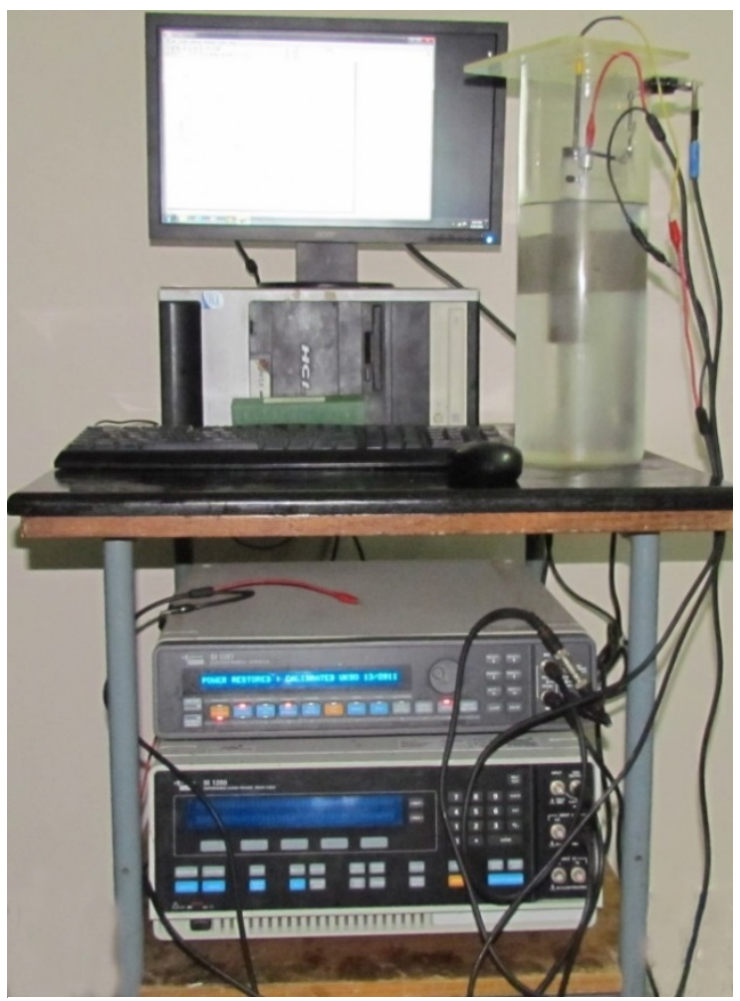

Figure 4. Corrosion test setup with corrosion cell, potentiostat, and computer.

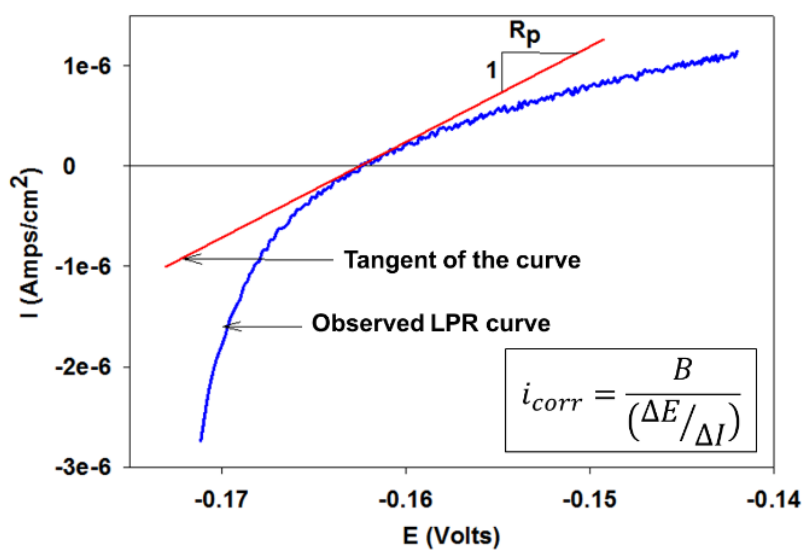

Figure 5. A typical linear polarization resistance (LPR) curve. 


\section{RESULTS AND DISCUSSION}

\subsection{Measured corrosion rate}

As mentioned earlier, this paper focuses only on $t_{p}$, which is dependent on $\mathrm{i}_{\text {corr. }}$. Figure 6 shows the measured $\mathrm{i}_{\text {corr }}$ during the first 9 months of cyclic wetdry exposure. It shows that the $i_{\text {corr }}$ value is stabilized from 3 months of exposure onwards. The $i_{\text {corr }}$ obtained between 3 and 9 months were used for estimating $t_{p}$.

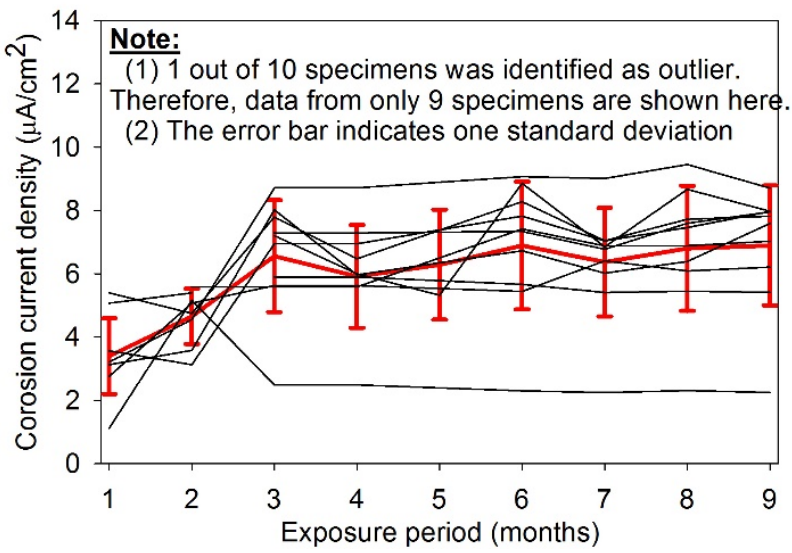

Figure 6. Average corrosion current density of 10 specimens.

Assuming a normal distribution for the $\mathrm{i}_{\text {corr }}$ data is mathematically incorrect. This is because a normal distribution can generate negative numbers for $\mathrm{i}_{\text {corr }}$, which is incorrect and can cause mathematical difficulties during simulation studies. It was found that a 3-parameter lognormal distribution is suitable to represent the observed $i_{\text {corr }}$ data. If $X$ is a random variable that has a 3-parameter lognormal distribution, then $Y=\ln (X-\gamma)$ has a normal distribution with mean, $\mu$, and variance, $\sigma^{2}$. The probability density function (PDF) of the 3-parameter lognormal distribution, $\operatorname{LN}(\mu, \sigma, \gamma)$, is calculated using Eq. 2.

$$
f(x ; \mu, \sigma, \gamma)=\frac{\exp \left\{-\frac{[\ln (X-\gamma)-\mu]^{2}}{2 \sigma^{2}}\right\}}{(X-\gamma) \sigma \sqrt{2 \pi}}
$$

where, $\mu$ is the scale parameter; $\sigma$ is the shape parameter, $\mathrm{Y}$ is the location or threshold parameter. The limiting values of these parameters are: $-\infty<\mu<\infty, \sigma>0$, and $\quad X>\gamma \geq 0$. Based on the Shapiro-Wilkinson normality test, the natural logarithm of $i_{\text {corr }}$ [i.e., $\ln \left(i_{\text {corr }}\right)$ ] followed a normal distribution. Therefore, it can be assumed that $\mathrm{i}_{\text {corr }}$ data follows a 3-parameter lognormal distribution $[\operatorname{LN}(\mu, \sigma, \gamma)]$. The mean and standard deviation of the random variable, $X$, can be calculated by substituting the lognormal parameters in Eq. 3 and Eq. 4, respectively.

$$
\operatorname{Mean}(X)=\gamma+\exp \left(\mu+\frac{\sigma^{2}}{2}\right)
$$

$$
S D(X)=\left(\exp \left(2 \mu+\sigma^{2}\right)\left(\exp \left(\sigma^{2}\right)-1\right)\right)^{0.5}
$$

where $S D$ is the standard deviation. To confirm the obtained estimates, the EasyFit software program was used to obtain the parameter estimates as follows:

$$
\begin{aligned}
\mathrm{i}_{\text {corr }} & \sim \operatorname{LN}(\mu, \sigma, \mathrm{y}) \\
& \sim \operatorname{LN}(4.2,0.03,-60.8)
\end{aligned}
$$

Figure 7 shows the histogram of the measured $\mathrm{i}_{\text {corr }}$ data and the PDF of the representative lognormal distribution in Eq. 5.

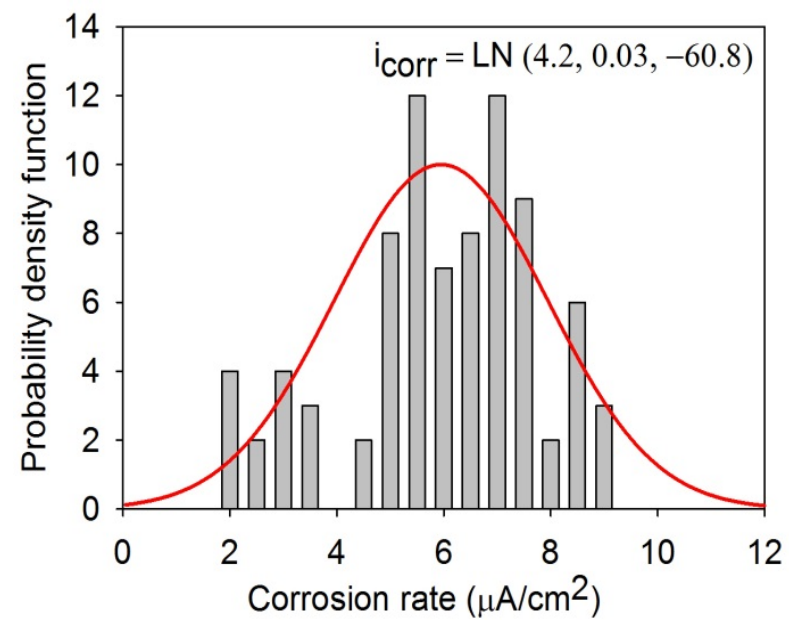

Figure 7. Probability density function for icorr $\sim \operatorname{LN}(4.2,0.03,-60)$.

\subsection{Probabilistic estimation of corrosion propagation periods}

All the two models viz., Morinaga (1990) and Wang and Zhao (1993) consider the $\mathrm{i}_{\text {corr }}$ as an input parameter. In addition to the $\mathrm{i}_{\text {corr }}$, the model by 
Morinaga (1990) considers the cover depth, $C_{v}$, as an input parameter. The model by Wang and Zhao (1993) considers both compressive strength, $f_{c u}$, and $C_{v}$ as influencing parameters, to estimate the crack initiation period. Figure 8 shows the PDF obtained using $i_{\text {corr }} \approx L N(4.2,0.03,-60.8)$ and the two existing models being studied.

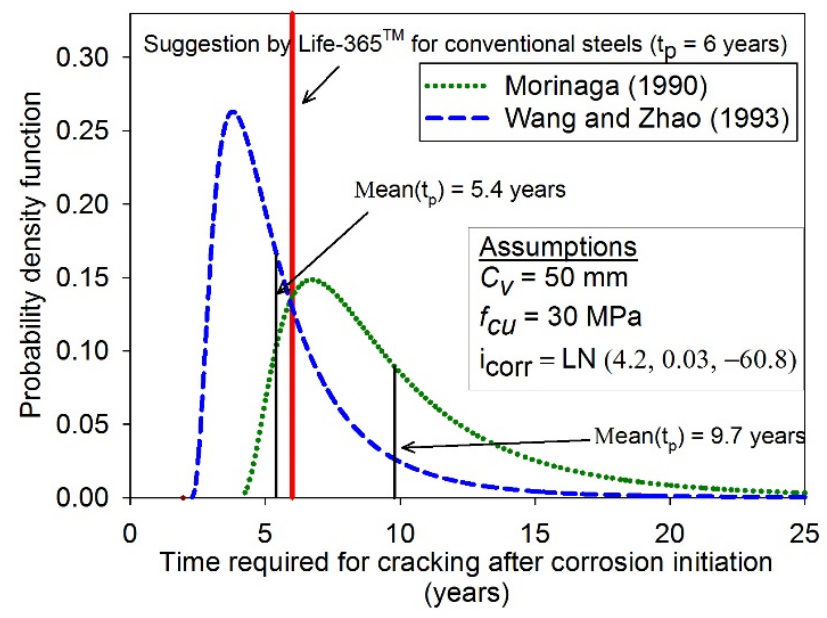

Figure 8. Time required for the cracking of cover concrete using the measured $i_{\text {corr }}$ data.

The models by Morinaga (1990) and Wang and Zhao (1993) estimate an average $t_{p}$ of 9.7 and 5.4 years, respectively, with a standard deviation of 1.6 years. These estimations are different from the deterministic $t_{p}$ of 6 years recommended by Life- $365^{\mathrm{TM}}$ software program. The Wang and Zhao (1993) model provides a closer estimation to the Life- $365^{\mathrm{TM}}$ estimation and provides more conservative result than the Morinaga (1990) model. Also, as mentioned earlier, the Wang and Zhao (1993) model may be more realistic than Morinaga (1990) model because of former model's dependence on both $\mathrm{C}_{\mathrm{v}}$ and $\mathrm{f}_{\mathrm{cu}}$.

\subsection{Effect of cover depth $\left(C_{v}\right)$ on propagation $\operatorname{period}\left(t_{p}\right)$}

Figure 9 shows the effect of $\mathrm{C}_{\mathrm{v}}$ on $\mathrm{t}_{\mathrm{p}}$ estimated by substituting the $\mathrm{i}_{\text {corr }} \sim \operatorname{LN}(4.2,0.03,-60.8)$ into the Morinaga (1990) and Wang and Zhao (1993) models. The Morinaga (1990) model (dotted curves) shows significant scatter in the estimated $t_{p}$ than the Wang and Zhao (1993) model (solid curves). For the case of $C_{v}=50 \mathrm{~mm}$, Morinaga (1990) and Wang and Zhao (1993) show a mean $t_{p}$ of 9.7 and 5.4 years, respectively. For the case of $C_{v}=65 \mathrm{~mm}$, these models show a mean $t_{p}$ of 12 and 6.3 years, respectively. Similarly, for the case of $C_{v}=80 \mathrm{~mm}$, these models show a mean $t_{p}$ of 14.3 and 7.1 years, respectively. Based on these mean estimations, it is found that Morinaga (1990) and Wang and Zhao (1993) models show that increasing the $C_{v}$ by $15 \mathrm{~mm}$ can increase the estimated $t_{p}$ by approximately 2.3 and 0.9 years, respectively. This difference of 2.3 and 0.9 years is obtained by taking the difference between the mean values of the data corresponding to $\mathrm{C}_{\mathrm{v}}=50 \mathrm{~mm}, 60 \mathrm{~mm}$ and $80 \mathrm{~mm}$ represented by the three dotted curves and the corresponding solid curves, respectively, in Figure 9. It can be concluded that the $\mathrm{C}_{\mathrm{v}}$ will have minimal influence on $t_{p}$.

In the model by Wang and Zhao (1993), the tensile stress created on the cover concrete due to the corrosion of steel bar and the strength of the concrete is considered, therefore it shows a short $t_{p}$ of 0.9 years. However, in the model by Morinaga (1990), the $t_{p}$ is estimated based on the quanity of corrosion product formed to initiate cracking; but, the additional stress taken by the cover concrete is neglected. Hence, it estimates longer $t_{p}$ than that obtained using Wang and Zhao (1993) model. It should also be noted that the Life$365^{\mathrm{TM}}$ assumes same $t_{p}$ value of 6 years for concretes with various $\mathrm{C}_{\mathrm{v}}$ and $\mathrm{f}_{\mathrm{cu}}$.

These estimated distributions indicate that the $t_{p}$ has significant scatter and the mean values can be between 5 to 10 years-giving very little time for planning the repair activities. This also suggests to have frequent inspections on prestressed concrete structures.

\section{CONCLUSIONS}

Based on the experimental program and the Morinaga (1990) and Wang and Zhao (1993) models discussed in this paper, the following conclusion are drawn. 


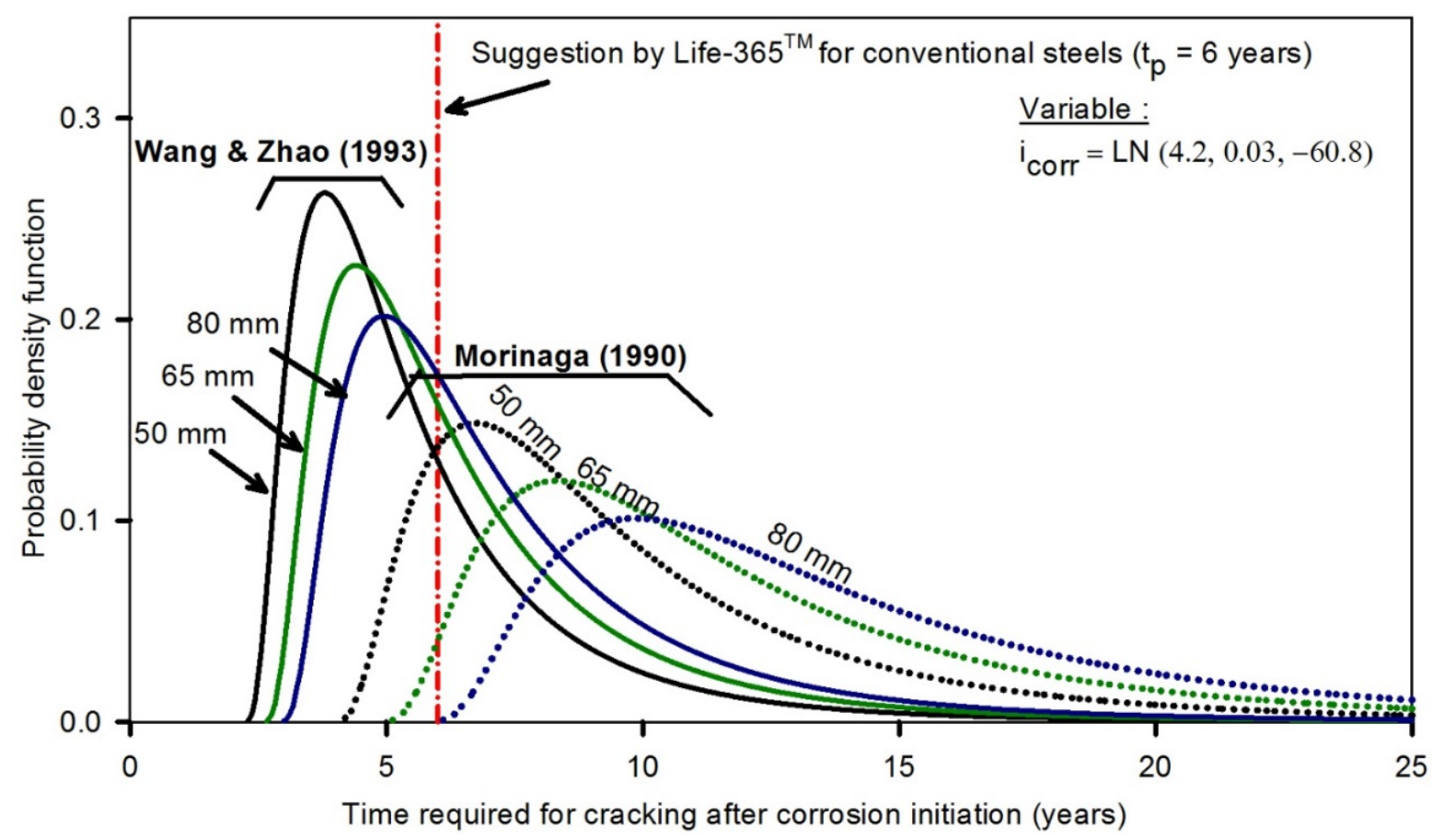

Figure 9. Corrosion propagation period for systems with different cover depths.

- When subjected to a cyclic wet-dry exposure to chloride environment, the corrosion rate, $\mathrm{i}_{\text {corr }}$, of prestressing steels can follow a 3-parameter lognormal distribution as follows: $\operatorname{LN}(\mu, \sigma, \gamma) \sim \operatorname{LN}(4.2,0.03,-60.8)$,

- The corrosion propagation period, $t_{p}$, for prestressed concrete systems exhibit significant scatter and the mean values can be between 5 and 10 years, if the cover depth is $50 \mathrm{~mm}$.

- The average increase in the corrosion propagation period due to an increase of $15 \mathrm{~mm}$ in the cover depth can be between 0.9 to 2.3 years.

\section{ACKNOWLEDGEMENTS}

The authors acknowledge the support provided by the Department of Science and Technology (DST), Government of India (DST Fast-track Grant No. SR/FTP/ETA-0119/2011) and the Department of Civil Engineering, Indian Institute of Technology Madras, Chennai, India to carry out this research. The experimental assistance provided by Mr. Prasanth Alapati, Ms. Ranjitha Rajagopal, Mr. Krishnan, Ms. Malarvizhi, and Mr. Murali is also highly appreciated.

\section{REFERENCES}

Ahmad, S. (2003). Reinforcement corrosion in concrete structures, its monitoring and service life prediction-a review. Cement and Concrete Composites, 25, 459-471.

Andrade, C., \& Alonso, C. (2001). On-site measurements of corrosion rate of reinforcements. Construction and Building Materials, 15, 141-145.

ASTM G1. (2011). Standard Practice for Preparing, Cleaning, and Evaluating corrosion Test Specimens, American Society of Testing and Materials (ASTM), Conshohoken, PA, USA.

BIS. (2002). Specification for coarse and fine aggregates from natural sources for concrete. IS 383:2002, Bureau of Indian Standards (BIS), New Delhi, India.

Morinaga, S. (1990). Prediction of service lives of reinforced concrete buildings based on the corrosion rate of reinforcing steel. Proceedings of Building Materials and Components, Brighton, UK. 7-9, November, 5-16.

Tait, W. S. (1994). An introduction to electrochemical corrosion testing for practicing engineers and scientists. Pair O'Docs Publications, Racine. Wisconsin.

Tutti, K. (1982). Corrosion of steel in soncrete. Report No. Fo. 4. Swedish Cement and Concrete Research Institute, Stockholm, Sweden.

Wang X. M., \& Zhao, H. Y. (1993). The residual service life prediction of R.C. structures. In: S. Nagataki (Ed.), Durability of building materials and components 6, 1107-1114. 